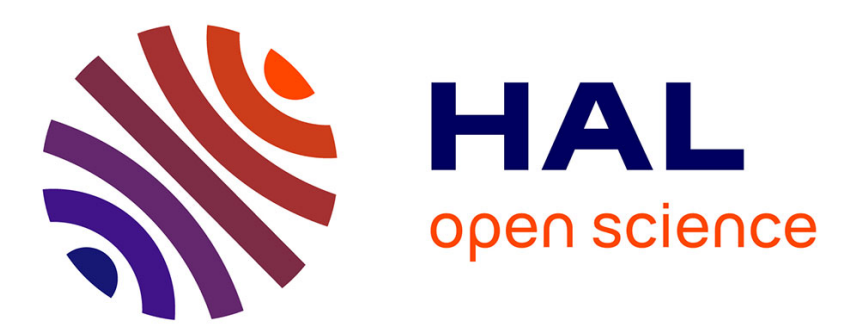

\title{
Effect of Hydrogen Precharging on Grain Boundary Relaxation in Iron of High Purity
}

E. Lunarska, Y. Jagodzinski, Y. Ososkov

\section{To cite this version:}

E. Lunarska, Y. Jagodzinski, Y. Ososkov. Effect of Hydrogen Precharging on Grain Boundary Relaxation in Iron of High Purity. Journal de Physique IV Proceedings, 1996, 06 (C8), pp.C8-353-C8-356. 10.1051/jp4:1996876 . jpa-00254684

\section{HAL Id: jpa-00254684 https://hal.science/jpa-00254684}

Submitted on 1 Jan 1996

HAL is a multi-disciplinary open access archive for the deposit and dissemination of scientific research documents, whether they are published or not. The documents may come from teaching and research institutions in France or abroad, or from public or private research centers.
L'archive ouverte pluridisciplinaire HAL, est destinée au dépôt et à la diffusion de documents scientifiques de niveau recherche, publiés ou non, émanant des établissements d'enseignement et de recherche français ou étrangers, des laboratoires publics ou privés. 


\title{
Effect of Hydrogen Precharging on Grain Boundary Relaxation in Iron of High Purity
}

\author{
E. Lunarska, Y. Jagodzinski* and Y. Ososkov
}

Institute of Physical Chemistry, Polish Academy of Sciences, 01-224 Warsaw, ul. Kasprzaka 44/52,

Poland

* Institute of Metal Physics, National Academy of Sciences of Ukraine, Kiev, Ukraine

\begin{abstract}
Irreversible change of grain boundary structure due to the different hydrogen charging of annealed and cold worked iron of high purity was studied by internal friction measurements of grain boundary relaxation. Two relaxation modes are involved in the main process of grain boundary relaxation: high temperature mode associated with the GB sliding, and low temperature mode associated with the motion of near grain boundary dislocations.
\end{abstract}

\section{INTRODUCTION}

Mechanism of grain boundary (GB) relaxation has been still discussed: GB sliding, motion of grain boundary or lattice dislocation, and operation of severa 1 mechanisms have been considered [1]. The further understanding of the role of individual processes in GB relaxation may be achieved by application of material treatment providing the change of $G B$ structure and not affecting the other structural features of metal. In present work, the structural features, responsible for GB relaxation were studied by internal friction measurements of differently precharged iron of high purity. The nucleation and propagation of grain boundary microvoids formed in iron, charged with hydrogen above the critical content $\left(C_{v}\right)$ [2], modify the structure of $G B$ and adjacent material, without affecting the material grain size or GB chemistry. Therefore, any change of $G B$ internal friction due to hydrogen precharging could be attributed to the change in the GB structure.

\section{EXPERIMENTAL}

Iron containing $6 \mathrm{ppm}(C+N)$ was studied in cold worked (80\%RA) and annealed (970K) conditions. The grain size was 301 in first, and 951 in a latter case. Specimens were cathodically polarized for $48 \mathrm{hrs}$ at $5 \mathrm{~mA} / \mathrm{cm}^{2}$ in pure $1 \mathrm{~N} \mathrm{H}_{2} \mathrm{SO}_{4}$ or in $1 \mathrm{~N} \mathrm{H}_{2} \mathrm{SO}_{4}+5 \mathrm{mg} / 1 \mathrm{As}_{2} \mathrm{O}_{3}$ in order to attained the undercritical and overcritical hydrogen content, respectively [3]. After charging, specimens were totally degassed in vacuum at 300K for $2 \mathrm{hrs}$ and then at RT for $48 \mathrm{hrs}$.

Internal friction was measured by inverted torsion pendulum at frequency about $5 \mathrm{~Hz}$ within the temperature range $300-970 \mathrm{~K}$ at heating rate $2 \mathrm{~K} / \mathrm{min}$. Background was extracted according to [4], and peaks were processed using "Picfit" program (Jandel Scient if ic $\mathrm{Co}$ ) and log normal distribution.

\section{RESULTS}

Overcritically precharged iron exhibited the grain and subgrain microcrevices, observed by optical microscopy (Figure la). Undercritical hydrogen charging produced no such microcrevices; however, the microdimples on gra in boundary surface seen after tensile fracture (Figure $1 b$ ) implied the existence of grain 

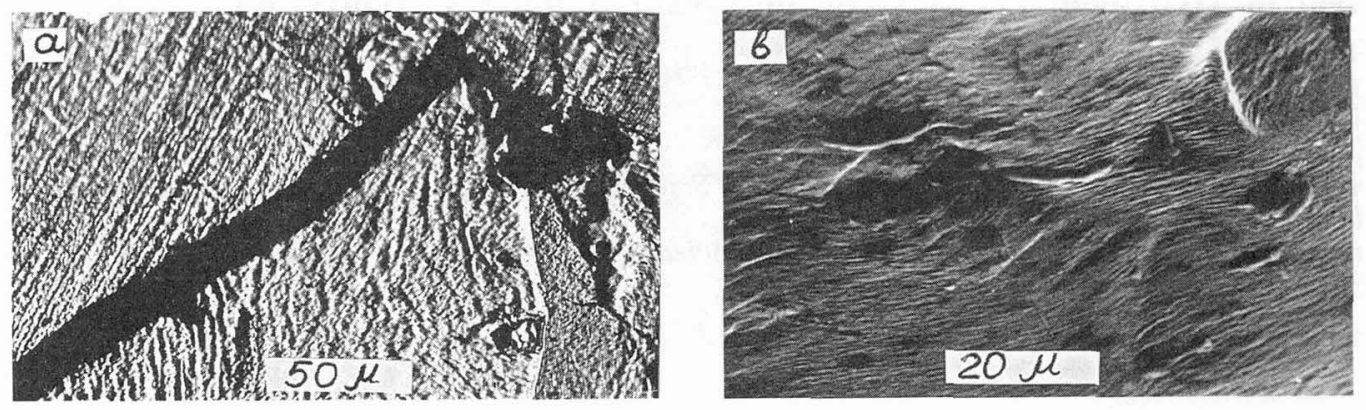

Figure 1: Hydrogen induced metal degradation. a) Intergranular microcrevices formed in cold worked iron due to overcritical precharging; b) Intergranular microdimples seen on the grain boundary surface after tensile test.

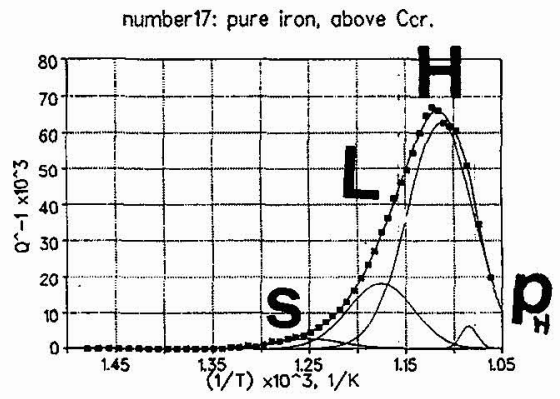

Figure 2. The example of deconvolution of $G B$ internal friction peaks.
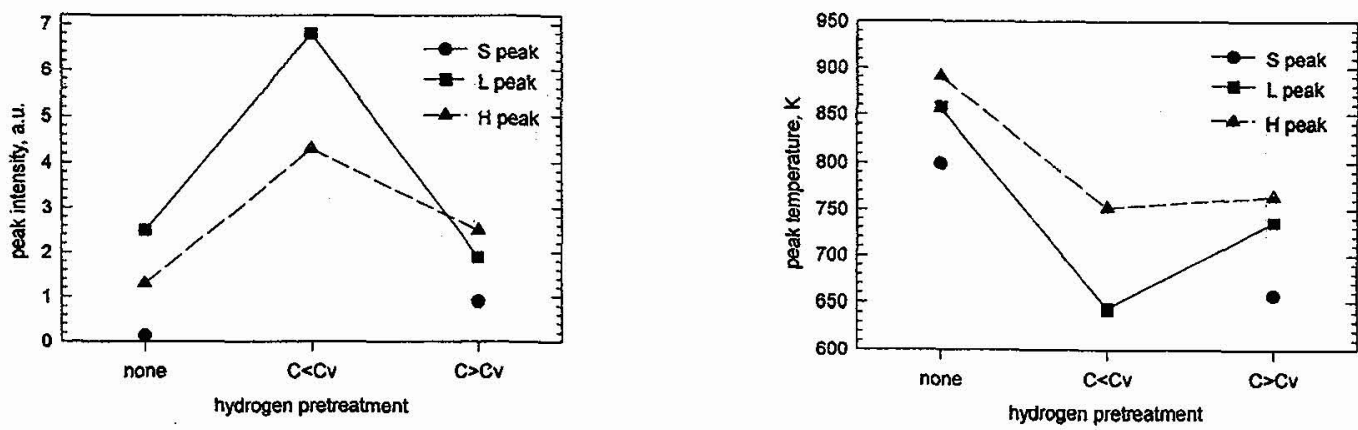

Figure 3. Effect of hydrogen precharging on parameters of internal friction peaks recorded for annea led iron.
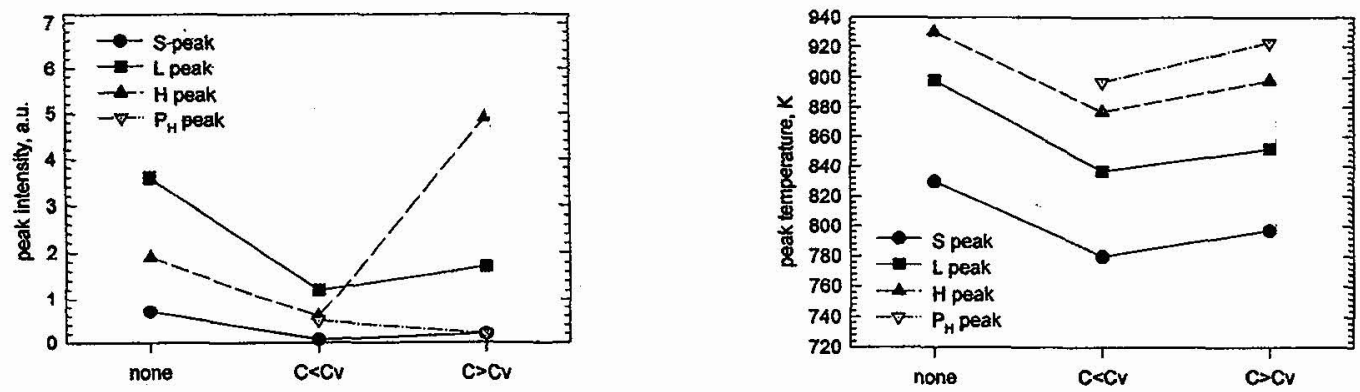

Figure 4. Effect of hydrogen precharging on parameters of internal friction peaks recorded for cold worked iron. 
boundary submicrovoids or at least the low grain boundary cohesion.

For all specimens, the internal friction spectra contained the low temperature satellite $(S)$, and the main peak which was deconvoluted into the low temperature $(L)$ and high temperature $(H)$ components (Figure 2 ). In the case of cold work hydrogen pretreated iron, the optimum deconvolution was achieved at resolution of additional peak $\left(P_{B}\right)$. Since the peaks broadening, their intensity was measured as an area beneath the peaks. Parameters of deconvoluted peaks are presented in Figures 3 and 4.

Undercritical hydrogen pretreatment shifted the satellite peak $S$ and the $L$ and $H$ components of ma in peak to lower temperature. The effect was more pronounced in annealed (Figure $3 a$ ) than in cold worked (Figure 4a) material. Overcritical pretreatment caused some recovery of peaks temperature, in comparison with undercritical treatment.

The intensity of $L$ and $H$ components increased in annealed material due to undercritical treatment; further hydrogen charging caused the decrease in both peaks (Figure 3b). For cold worked material, the undercritical treatment decreased both components, and the overcritical treatment recovered the peaks height; peak $H$ became higher than in initial state (Figure $4 b$ ). Intensity of satellite peak $S$ decreased after undercritical and recovered after overcritical pretreatment for both states of material.

The additional peak $P_{z}$ had lower intensity and higher temperature in undercritical than in overcritical state (Figure 4 ).

\section{DISCUSSION}

The applied "hydrogen charging - degassing" treatment of specimens caused the internal friction measurements to detect the irreversible effects of material structure produced during hydrogen charging of specimens.

The process of GB degradation at increasing fugasity of hydrogen can be described as follows. Hydrogen produces the lattice dilatation [5], and its segregation at GB causes the local stress concentration, which can relax by the formation of vacancies at grain boundaries. The excess of hydrogen induced vacancies can be, in turn, relaxed by the formation of dislocation loops around GB [6] and by coagulation of vacancies [7]. Presence of vacancies and their conglomerates should decrease the $G B$ cohesion, as may be concluded by the appearance of fracture surface of hydrogen pretreated iron, cf. Figure $1 \mathrm{~b}$. The vacancy conglomerates provide also the sites for hydrogen recombination; this promotes (at still increasing fugasity) the formation of intergranular microcrevices. At the presence of microcrevices, the near grain boundary dislocation structure relax due annihilation of dislocation at the crevice walls.

According to above mechanism, the following changes in grain boundary structure, affecting the $G B$ relaxation process are expected in hydrogen precharged iron: 1) modification of near grain boundary dislocation network; and 2) modification of $G B$ viscosity and cohesion due to the formation of $G B$ vacancies. In agreement with above predictions and ideas in [8], the observed in our work low temperature component $L$ of main peak was accounted by anelastic response of lattice dislocations adjacent to grain boundaries, and the high temperature component $H$ was accounted for GB sliding. The change of the parameters of those peaks at hydrogen charging supported the above assumptions.

Hydrogen induced shift of $L$ and $H$ peaks to lower temperature may be a result of increase in the vacancy content at grain boundary [9]. The excess vacancies can facilitate the dislocation climbing in the vicinity of grain boundaries due to the possible decrease in their effective viscosity, and thus can shift $L$ component to lower temperature. Presence of high number of vacancies within the grain boundary should decrease the viscosity of grain boundary for sliding, and thus should decrease the temperature of respective peak $H[10]$. 
Overcritical charging produced the recovery of $L$ and $H$ components. This may be a result of decrease in the number of vacancies at microvoid formation.

Change of intensity of $L$ component due to hydrogen treatment may confirm the near grain boundary lattice dislocations as a source of relaxation. Undercritical hydrogen treatment of annealed specimens causing emission of dislocations, should intensify the dislocation relaxation and height of $L$ component. At undercritical hydrogen charging of cold worked iron, more complex and stable dislocation structures was formed causing decrease in $L$ intensity.

At formation of microvoids (overcritical precharging), the decrease in $L$ component for annealed material (Figure $3 \mathrm{~b}$ ) is associated with the decrease in dislocation density in the near GB areas due to their annihilation in microvoids. In cold work material, annihilation of dislocation in microvoids could result in relaxation of dislocation network. As a result, the higher anelastic response is produced, reflected by some increase in $L$ component (Figure 4b). Different effect of hydrogen precharging on annealed and cold worked material could be also seen from the appearance of additional peak $\mathrm{PB}_{\mathrm{B}}$ (Figure 4 ) in a latter case.

Increase in $H$ component after overcritical treatment of cold work iron might be accounted by the hydrogen effect on three grains joint sites, which are susceptible to microvoids nucleation, especially in cold work material [2]. In this case, the joints could not serve as the obstacles for grain boundary sliding any more, and peak $H$ should increase.

The satellite peak resembled the low temperature satellite peaks ( $\mathrm{P}_{\mathrm{so}}$, $P_{150}$ ) observed in [8], and it is apparently associated with the anelastic response of the lattice dislocations within the grain bulk. For some specimens, it can be hardly resolved from the $L$ peak.

\section{CONCLUSIONS}

From the results of internal friction measurements of hydrogen precharging pure iron, the following conclusions could be drawn.

1. Hydrogen charging of pure iron, even to the content lower than the critical one, causes irreversible changes of $G B$ structure.

2. Formation of vacancies at $G B$ and change of near grain boundary dislocation arrangement due to hydrogen precharging are detected by the change of the high temperature and low temperature internal friction peaks, confirming the existence of different modes in GB relaxation process.

\section{References}

1. Molinas B.J. and Povolo F.,, Mater. Sci. Forum, 119-121 (1993) 39-45

2. Lunarska E., Scripta Meta7., 15 (1981) 1149-1153

3. Lunarska E., Jagodzinski $Y$. and Ososkov Y., Phys. Stat. Sol. (a), to be published, 1996

4. No M.L., San Juan J., Esnouf C., Fantozzi G. and Bernalte A., J. Physique, 44 (1983) C9-751-765

5. Hirth J.P., Metal. Trans., 11A (1980) 861-870

6. Ha K.F., Zhang L.W. and Liu B.Z., Metal Trans., 20 A (1989) 2379-2382

7. Jagodzinski J., Larikov L. and Smouk A., "Void Formation in Hydrogen Charged Metals Induced by Plastic Deformation as the Initial Stage of Embrittlement", IV Intern. Conf. "Hydrogen Effects on Materials

Behavior", Moran, Wyoming, USA, September 1994

8. Iwasaki K., Phys.Sta.Sol (a), 81 (1984) 485-496

9. Totsky A. Yu., Mater. Sci. Forum, 119-121 (1993) 291-294

10 T. S. Ke, Scripta Meta7. Mater., 24 (1990) 347- 352 